\title{
Upper-Bound Analysis for Equal Channel Angular Pressing (ECAP) with an Intersecting Channel Angle of $120^{\circ}$
}

\author{
Jailson da Silva ${ }^{a}\left(\mathbb{0}\right.$, Pablo Almeida Santos ${ }^{a}$, Ricardo Kirchhof Unfer ${ }^{a}$, Guilherme Ourique Verran ${ }^{a}$, \\ Athos Henrique Plaine ${ }^{*}$ (1) \\ ${ }^{a}$ Universidade do Estado de Santa Catarina, Programa de Pós-Graduação em Ciência e Engenharia de \\ Materiais, Joinville, SC, Brasil.
}

Received: June 28, 2021; Revised: August 27, 2021; Accepted: September 5, 2021

\begin{abstract}
The exact calculations of the stress and strain distributions based on the controlling equations for a forming process with large deformation are often difficult. To circumvent such difficulties, some analytical methods such upper-bound analysis and slip-line field theory have been established by making a number of simplifying assumptions regarding the material properties and deformation modes. In this work an analytical model based on the upper-bound theory was successfully developed to predict material flow pattern and maximum process loads for an Equal Channel Angular Pressing (ECAP) die with circular cross-section and an intersecting channel angle of $120^{\circ}$. Based on the model, the power dissipated on all frictional and velocity discontinuity surfaces were determined and optimized in order predict the maximum process force as function of the channel geometry and the material plastic behavior. To validate the developed model, the ECAP die were produced and used to determine experimental load-displacement curves of AA6061-T6 specimens with different lengths. A good correlation between theoretical and experimental results was observed. In addition, the constant friction factor demonstrated to have a strong effect on the relative extrusion pressure.
\end{abstract}

Keywords: severe plastic deformation; equal channel angular pressing; upper-bound analysis; constant friction factor.

\section{Introduction}

Over the past decades, producing bulk ultrafine-grained (UFG) and nanostructured materials through the application of severe plastic deformation (SPD) methods has attracted a considerable interest in the field of materials science and engineering ${ }^{1}$. The most popular method of SPD is Equal Channel Angular Pressing/Extrusion (ECAP/ECAE), an innovative process capable of producing relatively uniform intensive plastic deformation in a variety of material systems, without causing substantial change in geometric shape or cross section $^{2}$. For medical grade alloys, ECAP has also proved to be efficient in improving biocompatibility, cell adhesion and proliferation ${ }^{3}$, besides presenting a better combination between mechanical resistance and ductility compare to others conventional forming processes ${ }^{4,5}$.

During ECAP processing, a sample with square or round cross-section is pressed into a die with two intersecting channels of equal cross-section area. As the sample is pressed using a plunger, it shears at the intersection and exits through the second channel. All of the material passes through the intersecting section and experiences shear strain. As the cross-section is symmetric, the sample can be rotated before reentry into the die. Critical ECAP process variables include the die angle, temperature, number of passes through the die, and whether or not the specimen is rotated between passes ${ }^{6,7}$.

*e-mail: athos.plaine@udesc.br
The successful implementation of ECAP to process different materials and alloys relies on the design, control and optimization of the forming process. Therefore, knowledge regarding the deformation patterns and stresses (loads), which are directly associated with lubrication, material handling, die design and manufacture, is required. Thus, compared with traditional time consuming trial-and-error methods, modeling is an efficient way to acquire such important information. Therefore, to circumvent the mathematical complexity of calculating the exact stress and strain distributions based on the controlling equations for a forming process with large deformation, analytical models such as upper-bound analysis and slip-line field theory have been established by making a number of simplifying assumptions regarding the material properties and deformation modes 8 .

With respect to slip-lines analysis for ECAP, Segal et al. ${ }^{9-11}$ already provided a fundamental analysis of the deformation behavior of the material over the process, demonstrating that plastic deformation can be spread out across a certain volume in the region shared by the entrance and exit channels, and that the shape of that volume depends on friction, strain hardening, and back-pressure. However, there are inherent difficulties in the construction of slip-line fields, especially when the deformation areas are irregular or boundary conditions involve both velocity and traction components. 
Upper-bound analysis ignores the stress equilibrium equations and predicts higher load levels than the exact solution, being very useful in predicting the punch pressure and flow patterns in forming processes. However, the core procedure of the upper-bound approach is the construction of a geometric consistent velocity field. This may be difficult under certain circumstances especially if the flow pattern is complicated by factors such as material properties, boundary condition, and temperature effects ${ }^{12}$. In 2006, Paydar et al. ${ }^{13}$ performed for the first time an upper-bound approach to analyze an ECAP die set with a circular cross-section and an intersecting channel angle of $90^{\circ}$, showing a good agreement between the theoretical and experimental load displacement curve. Medeiros et al. ${ }^{14}$ included the material strain-rate effects and two isotropic plasticity yield criteria in the model, showing that ECAP parameters most affecting the extrusion pressure are friction factor, intersection die channels angle, outer fillet radius and inner fillet radius. Since then, few other studies have been published on this subject, but they have originally been limited to $90^{\circ} \mathrm{ECAP}$ dies.

In this work, based on the upper-bound theory, an analytical model was developed for an ECAP die with circular crosssection and an intersecting channel angle of $120^{\circ}$. The effect of the length of the specimen and the constant friction factor on the relative pressure was investigated. In order to validate the results, the ECAP die were produced and used to determine experimental load-displacement curves.

\section{Experimental Procedure}

Load-displacement curves for AA6061-T6 aluminium alloy bars deformed by a single pass ECAP were obtained to validate the analytical model. The samples were produced in a shape of a rod with the diameter of $8 \mathrm{~mm}$ and tree different lengths: 10, 20 and $30 \mathrm{~mm}$. The ECAP processing was performed at room temperature in a die with channel

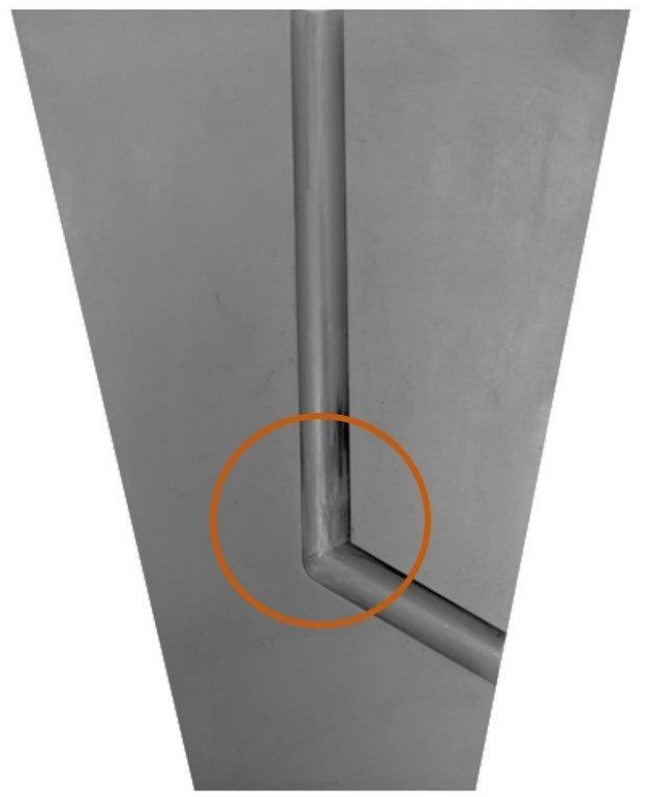

angles of $\Phi=120^{\circ}$ and $\psi=30^{\circ}$, with an extrusion speed of $5 \mathrm{~mm} / \mathrm{min}$. Table 1 lists the mechanical properties of the as-received AA6061-T6 alloy ${ }^{15}$. The photograph of the self-designed split die is shown in Figure 1. Due to the good formability of the alloy, crack free ECAP billets could be produced without the application of backpressure. Semi-solid Molybdenum disulphide was used as lubricant in order to reduce the friction between specimen surface and die wall.

Tensile tests were used to obtain the true stress-true strain curve of the base material, as shown in Figure 2, and the material plastic behavior equation was determined. Thus, the mean flow stress of $488 \mathrm{MPa}$ was estimated by integrating the equation between zero and the final equivalent strain of a single ECAP pass (Equation 2), $\varepsilon_{\text {eq }}=0.67$, calculating according to the von Mises equation (Equation 1$)^{16}$.

$$
\begin{aligned}
& \varepsilon_{e q}=\frac{1}{\sqrt{3}} \cdot\left[2 \cot \left(\frac{\varnothing}{2}+\frac{\Psi}{2}\right)+\Psi\left(\operatorname{cosec} \frac{\varnothing}{2}+\frac{\Psi}{2}\right)\right] \\
& \bar{\sigma}=\frac{1}{\varepsilon_{e q}} \int_{0}^{\varepsilon_{e q}} K \varepsilon^{n} d \varepsilon
\end{aligned}
$$

The constant friction factor $m$ was estimated by the "Barrel Compression Test" method ${ }^{17}$. Tests were performed in triplicate at room temperature and using the same lubricants as for ECAP. Figure 3 illustrates a simple representation of the compression test. By measuring top radius, maximum

Table 1. Mechanical properties of the as-received AA6061-T6 aluminium alloy ${ }^{15}$.

\begin{tabular}{ccccc}
\hline Alloy & $\begin{array}{c}\text { Yield } \\
\text { strength } \\
(\mathrm{MPa})\end{array}$ & $\begin{array}{c}\text { Tensile } \\
\text { strength } \\
(\mathrm{MPa})\end{array}$ & $\begin{array}{c}\text { Elongation } \\
(\%)\end{array}$ & $\begin{array}{c}\text { Hardness } \\
(\mathrm{HB})\end{array}$ \\
\hline AA6061-T6 & 300 & 330 & 15 & 95 \\
\hline
\end{tabular}

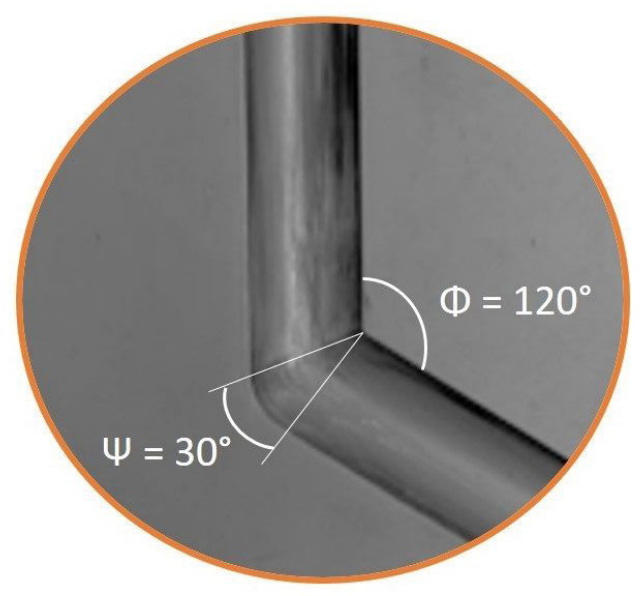

Figure 1. Self-designed split ECAP die with channel angles of $\Phi=120^{\circ}$ and $\psi=30^{\circ}$. 


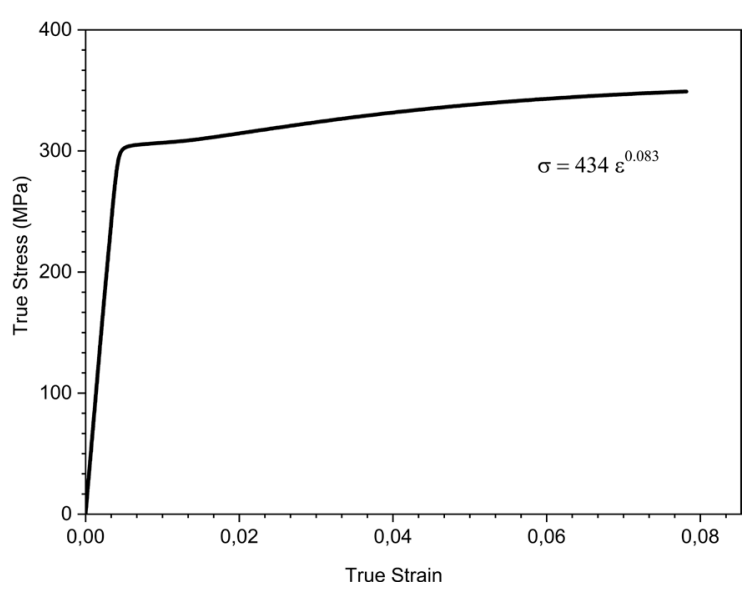

Figure 2. Stress-strain curves of AA6061-T6 aluminium alloy.

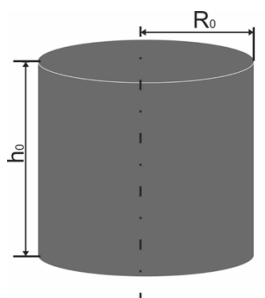

(a)

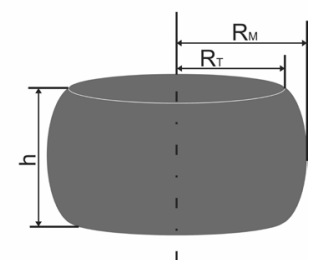

(b)
Figure 3. A simple representation of solid compression test and the measured parameters (a) before and (b) after compression.

radius and height of cylinder after deformation, the constant friction factor was estimated by using Equations 3 to 5 .

$\mathrm{m}=\frac{\left(\frac{\mathrm{R}}{\mathrm{h}}\right) \cdot \mathrm{b}}{\left(\frac{4}{\sqrt{3}}\right)-\left(\frac{2 \cdot \mathrm{b}}{3 \cdot \sqrt{3}}\right)}$

$\mathrm{b}=4 \frac{\Delta \mathrm{R} \cdot \mathrm{h}}{\mathrm{R} \cdot \Delta \mathrm{h}}$

$\mathrm{R}=\mathrm{R}_{0} \sqrt{\frac{h_{0}}{\mathrm{~h}}}$

where $\mathrm{b}$ is the barrel parameter; $\mathrm{R}$ is the average radius of cylinder after deformation; $\Delta \mathrm{R}$ is the difference between maximum and top radius; $\mathrm{R}_{0}$ is the initial radius of cylinder; $\mathrm{h}_{0}$ is the initial height of cylinder; $\mathrm{h}$ is the height of cylinder after deformation; $\Delta \mathrm{h}$ is the reduction of height of cylinder after deformation.

\section{Results and Discussion}

\subsection{Analytical model}

The upper-bound theorem was formulated in accordance with the theorem proposed by Prager and Hodger ${ }^{18}$, which states that the cinematically admissible velocity field that minimizes the power consumed during a metal-forming process, expressed by Equation 6, is the actual velocity field.
$\mathrm{P}=\int_{\mathrm{V}}^{\mathrm{a}} \bar{\sigma} \dot{\bar{\varepsilon}} \mathrm{dv}+\int_{\mathrm{Ss}}^{\mathrm{a}} \tau \dot{\mathrm{u}}_{\mathrm{i}} \mathrm{ds}+\int_{\mathrm{Sc}}^{\mathrm{a}} \mathrm{T} \dot{\mathrm{u}}_{\mathrm{i}} \mathrm{ds}$

The first term in the equation refers to the power dissipated due to the internal homogeneous deformation throughout the deforming volume $\mathrm{V}$. The second term expresses the power dissipated due to the velocity discontinuities surfaces, while the third term considers the friction losses over the toolmaterial interfaces ${ }^{19}$. In this work, the procedure adopted to formulate a solution for the proposed ECAP die was to divide its channel into three zones throughout each of which the velocity is continuous, as shown in Figure 4a.

In zones I and III, the material moves rigidly with the velocity of $\mathrm{V}_{0}$. In zone II, where the material is deformed plastically, the velocity field in cylindrical coordinates, assuming the entry velocity $\mathrm{V}_{0}$, is expresses as:

$$
\begin{aligned}
& V_{\theta}=V_{o} \cos \varphi \\
& V_{r}=V_{z}=0
\end{aligned}
$$

From the hodograph presented in Figure 4b, the shear velocity modulus at the discontinuity surfaces at entry and exit surfaces S1 and S4, respectively, are:

$$
\begin{aligned}
& \left|\Delta V_{O B}\right|=\left|\Delta V_{O D}\right|=V_{0} \sin \varphi \\
& \left|\Delta V_{B D}\right|=V_{0} \cos \varphi
\end{aligned}
$$

Moreover, based on the velocity field, the only components of strain rate in the deformation zone are:

$\dot{\varepsilon}_{r \theta}=\dot{\varepsilon}_{\theta r}=-\frac{V_{\theta}}{2}=-\frac{V_{0} \cos \varphi}{2 r}$

Hence, $\dot{\varepsilon}_{i j} \dot{\varepsilon}_{i j}=2 \dot{\varepsilon}_{r \theta}^{2}$ and the deformation rate of ideal work is given by:

$\dot{\bar{\varepsilon}}=\sqrt{\frac{1}{2}} \dot{\varepsilon}_{i j} \dot{\varepsilon}_{i j}=\dot{\varepsilon}_{r \theta}$

The total power consumption during ECAP process through the die is obtained by:

$\dot{\mathrm{W}}_{\mathrm{Total}}=\dot{\mathrm{W}}_{\mathrm{Ideal}}+\dot{\mathrm{W}}_{\mathrm{S}_{\mathrm{OB}}}+\dot{\mathrm{W}}_{\mathrm{S}_{\mathrm{OD}}}+\dot{\mathrm{W}}_{\mathrm{S}_{\mathrm{AOB}}}+\dot{\mathrm{W}}_{\mathrm{S}_{\mathrm{DOE}}}+\dot{\mathrm{W}}_{\mathrm{S}_{\mathrm{BOD}}}+\dot{\mathrm{W}}_{\mathrm{S}_{\mathrm{Entrance}}}$

where $\dot{\mathrm{W}}_{\text {Ideal }}$ is the power dissipated in the deformation zone (zone II), $\dot{\mathrm{W}}_{\mathrm{S}_{\mathrm{OB}}}$ and $\dot{\mathrm{W}}_{\mathrm{S}_{\mathrm{OD}}}$ are shear power dissipated at the surfaces of velocity discontinuity $\mathrm{S} 1$ and $\mathrm{S} 4$, respectively. $\dot{\mathrm{W}}_{\mathrm{S}_{\mathrm{AOB}}}, \dot{\mathrm{W}}_{\mathrm{S}_{\mathrm{DOE}}}, \dot{\mathrm{W}}_{\mathrm{S}_{\mathrm{BOD}}}$ are the frictional powers dissipated on the cylindrical die walls of zones I, III and II, respectively. $\dot{\mathrm{W}}_{\mathrm{S}_{\text {Entrance }}}$ is the frictional power dissipated due to the axial sliding velocity between the moving material and stationary ECAP die.

For a von Mises material with yield stress $2 \mathrm{k}$, the ideal plastic work dissipated in the volume $\mathrm{V}$ of deformation zone II is given by:

$\dot{\mathrm{W}}_{\text {Ideal }}=2 \mathrm{k} \int_{\mathrm{V}}^{\mathrm{a}} \sqrt{\frac{1}{2} \epsilon_{\mathrm{ij}} \epsilon_{\mathrm{ij}}} \mathrm{dv}$

$\dot{\mathrm{W}}_{\text {Ideal }}=2 \mathrm{k} \int_{\varnothing}^{\frac{\pi}{3}-2 \varnothing} \mathrm{a} \int_{0}^{\frac{2 \mathrm{a}}{\cos \varnothing}}\left(\frac{\mathrm{V}_{0} \cos \varnothing}{\mathrm{r}}\right)$ 


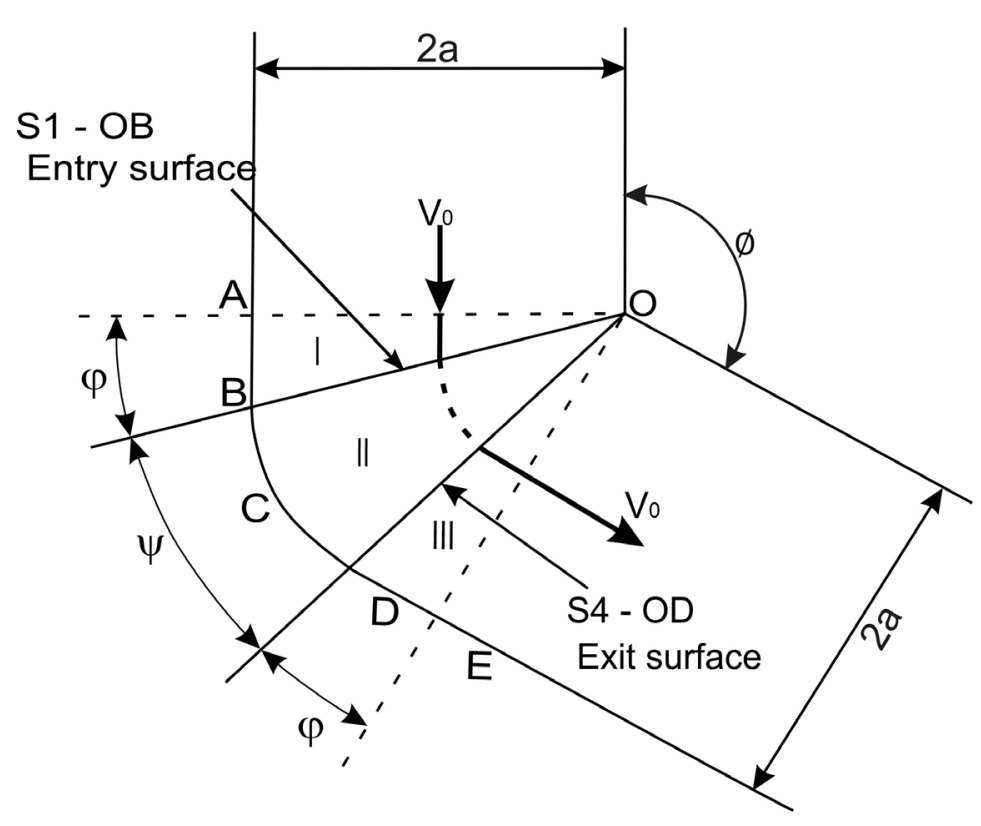

(a)

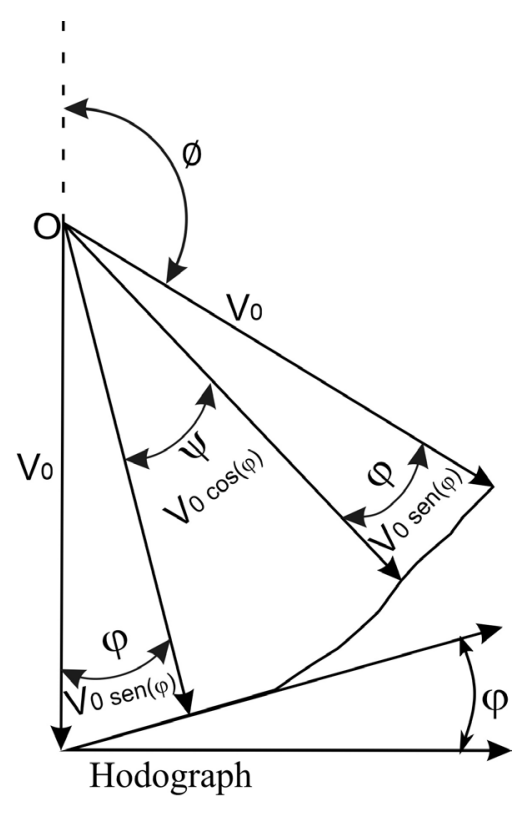

(b)

Figure 4. (a) Two-dimensional deformation model used in the ECAP process upper-bound analysis and (b) its hodograph.

$$
\dot{\mathrm{W}}_{\text {Ideal }}=\pi \mathrm{a}^{2} \mathrm{kV}_{0}\left(\frac{\pi}{3}-2 \varnothing\right)
$$

The power dissipated on the entrance and exit surfaces $\mathrm{S} 1$ and S4, in which the area of velocity discontinuity surfaces is equal to the area of an ellipse with the minor and major diameters of $2 \mathrm{a}$ and $\left(\frac{2 \mathrm{a}}{\cos \varnothing}\right)$, is given by:

$\dot{W}_{S_{O B}}=\dot{W}_{S_{O D}}=a \int_{0}^{R} k\left|\Delta V_{O D}\right| d r=k \pi a^{2} V_{0} \tan \varnothing$

The friction power dissipated at the cylindrical die walls AOB (zone I) and DOE (zone III), where $\Delta \mathrm{v}=V_{0}$ and $\Delta \mathrm{s}=2 \pi \mathrm{a}^{2} \tan \varnothing$, is given by:

$\dot{W}_{S_{A O B}}=\dot{W}_{S_{D O E}}=\int_{S_{D O E}}^{a} m k \Delta v d s=2 \pi a^{2} m k V_{0} \tan \varnothing$

For die wall BOD (zone II), $\Delta \mathrm{v}=V_{0} \cos \varnothing$ and $\mathrm{ds}=\left(\frac{\pi}{3}-2 \varnothing\right)\left(\operatorname{rsen} \varnothing^{2}+\operatorname{acos} \varnothing\right) \mathrm{dr}$, then:

$\dot{\mathrm{W}}_{\mathrm{sBODCB}}=\int_{0}^{\frac{2 \mathrm{a}}{\cos \varnothing}} \mathrm{mkV}_{0} \cos \varnothing\left(\frac{\pi}{3}-2 \varnothing\right)\left(\mathrm{rsen} \varnothing^{2}+\operatorname{acos} \varnothing\right) \mathrm{dr}($

$\dot{\mathrm{W}}_{\mathrm{SBODCB}}=2 \mathrm{a}^{2} \mathrm{mkV}\left(\frac{\pi}{3}-2 \varnothing\right)\left(\frac{\tan \varnothing^{2}}{2}+1\right) \cos \varnothing$

The frictional power dissipated at entry surfaces between moving material and stationary die up to line OA, considering that the current length of the plastic undeformed part of billet is equal to $1, \Delta \mathrm{v}=V_{0}$ and $\Delta \mathrm{s}=2 \pi \mathrm{al}$, is given by:

$\dot{\mathrm{W}}_{\text {Entrance }}=\int_{\mathrm{SF}}^{\mathrm{a}} \mathrm{mk} \Delta \mathrm{vds}=2 \pi \mathrm{alV} \mathrm{V}_{0} \mathrm{mk}$
Therefore, the total power dissipated during ECAP process is summarized as:

$$
\dot{\mathrm{W}}_{\text {Total }}=\pi \mathrm{a}^{2} \mathrm{kV}_{0}\left\{\begin{array}{l}
\left(\frac{\pi}{3}-2 \varnothing\right)+(2 \tan \varnothing)+(4 \mathrm{~m} \tan \varnothing)+ \\
\left(\frac{2 \mathrm{~m}}{\delta}\right)\left(\frac{\pi}{3}-2 \varnothing\right)\left(\frac{\tan \varnothing^{2}}{2}+1\right) \cos \varnothing+\left(2 \mathrm{~m} \frac{1}{\mathrm{a}}\right)
\end{array}\right\}
$$

By equating the above power to the external power, considering the angle relation $\psi=\frac{\pi}{3}-2 \varnothing$, the maximum extrusion force for ECAP process with circular cross-section and an intersecting angle of $120^{\circ}$ is obtained as:

$$
F_{\text {max }}=\pi a^{2} k\left\{\begin{array}{l}
\left(\frac{\pi}{3}-2 \varnothing\right)+(2 \tan \varnothing)+(4 \tan \varnothing)+ \\
\left(\frac{2 m}{\pi}\right)\left(\frac{\pi}{3}-2 \varnothing\right)\left(\frac{\tan \varnothing^{2}}{2}+1\right) \cos \varnothing+\left(2 m \frac{l}{a}\right)
\end{array}\right\}
$$

\subsection{Comparison of theoretical and experimental load-displacement curve}

The comparison between the theoretical ECAP forces and the experimental load-displacement curves for the tree different lengths of billets processed is presented in Figure 5. These results demonstrate an excellent agreement of the theoretical model with the experiments, having a maximum deviation of only $6 \%$. This deviation is mainly related to the simplifying assumptions made in the development of the model. As it is seen, the length of the billet and the ECAP force present a relationship of direct proportionality, that is, with the increase in the size of the billet there will be a greater area of contact with the ECAP die, which causes greater energy to overcome the static friction.

From these curves it is also possible to identify the presence of three stages of friction condition. The first stage 


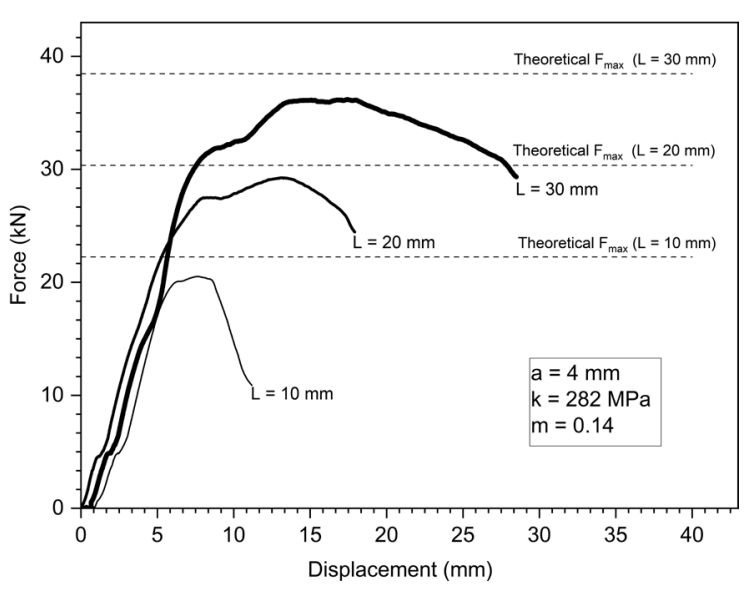

Figure 5. Experimental ECAP load-displacement curves at room temperature for different billet lengths: 10,20 and $30 \mathrm{~mm}$.

is direct compression and presents a linear shape, which is related only to static friction. Then, the second stage is characterized by a transition between the regions of static and dynamic friction. The third stage represents only the dynamic friction and, therefore, there is a reduction of the pressure force. Soon after reaching the maximum force, the curves gradually decrease as the frictional surface area in the entrance channel decreases with the advance of the punch. This curve shape is characteristic of extrusion processes and similar to those presented in previous works involving ECAP ${ }^{12,13}$.

Figure 6 compares the theoretical pressing forces for different diameters and a fixed billet length of $30 \mathrm{~mm}$ obtained in this study to the ones calculate from the upper-bound model developed by Paydar et al..$^{13}$ for a $90^{\circ}$ ECAP die, considering the same properties of the Al6061-T6 alloy of the this study. As expected, the reduction in the intersecting angle enhances the magnitude of plastic strain and also increases the work hardening phenomena, resulting in the highest force values.

Moreover, it is observed that a significant contribution to maximum theoretical force comes from the dissipation of frictional power at entry surfaces between moving material and stationary die, indicating a great dependence of the processing force with the friction factor $m$.

\subsection{Effect of constant friction factor}

The friction factor may vary from zero under frictionless condition to unity under full sticking. Figure 7 shows the variation of maximum ECAP force with the constant friction factor $m$ for three the tree different lengths of billets processed. As it is seen, friction has a strong effect on the relative ECAP forces. As previously shown, the third term of Equation 18 is the only one affected by the length of the billet, as it expresses the power dissipation by friction at the entry. Analyzing a frictionless condition $(m=0)$ the maximum extrusion force is reduced to about $12 \mathrm{kN}$, where $50 \%$ of the energy required for processing is consumed in the plastic deformation zone (Zone II) and the other 50\% in the Zones I and III (Figure 8a). On the other hand, if

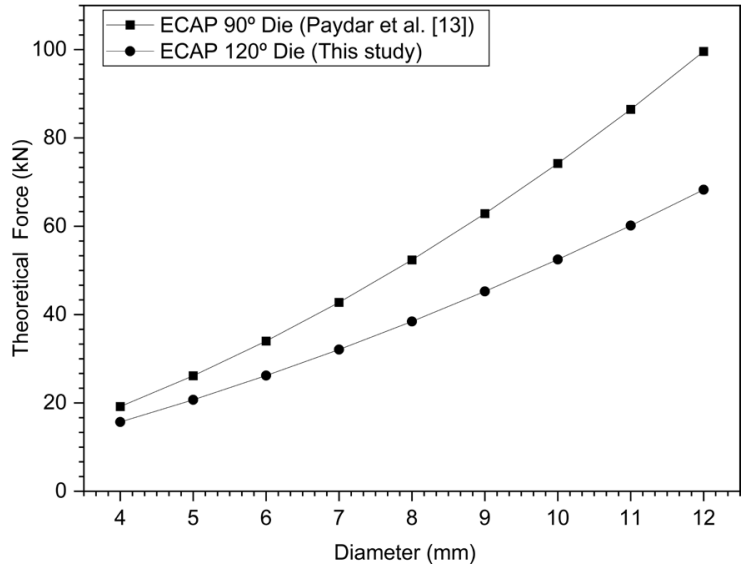

Figure 6. Theoretical pressing forces for different diameters and a fixed billet length of $30 \mathrm{~mm}$ for ECAP dies with intersecting angles of $90^{\circ 13}$ and $120^{\circ}$.

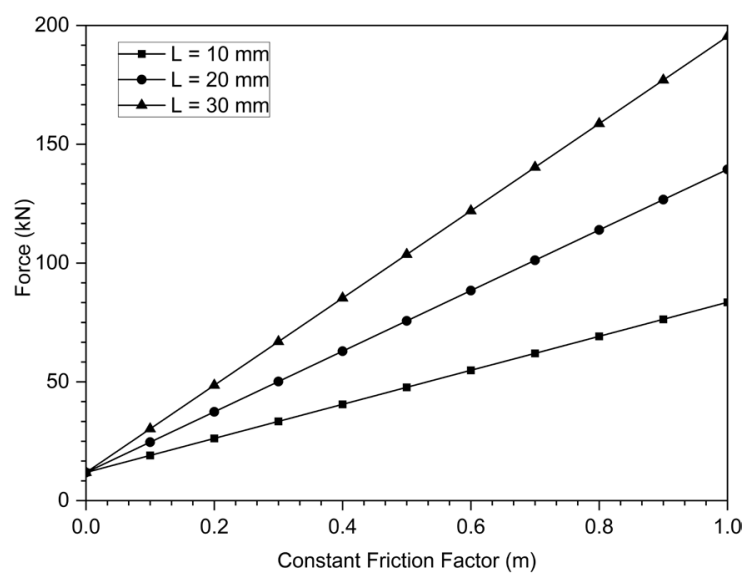

Figure 7. Effect of the friction factor on the maximum ECAP forces for different billet lengths.

the friction factor is close to 1 , the forces required to carry out the process are significantly increased, even for short billets, which can make the operation unpractical due to the excessive stresses applied on the punch. In this particular case, as observed in Figure 8c, 85\% of the process energy would be consumed to overcome the friction forces at the die entrance.

Therefore, to reduce the detrimental effects of friction, lubricants can be used extensively during ECAP. Moreover, lubrication is also beneficial in manipulating the material flow to achieve the desired end product, helping to prevent material sticking in the second channel and reducing extrusion force ${ }^{5}$. Paydar et al. ${ }^{13}$ analyzed the effect of the constant friction factor on a sharp intersecting ECAP die set with an intersecting channel angle of $90^{\circ}$. The results demonstrated that for constant friction factors close to zero the deformation zone occurs in a plane bounded by the intersection of two channels. While for constant friction factors more than 0.5 , the deformation zone develops to its largest size. 


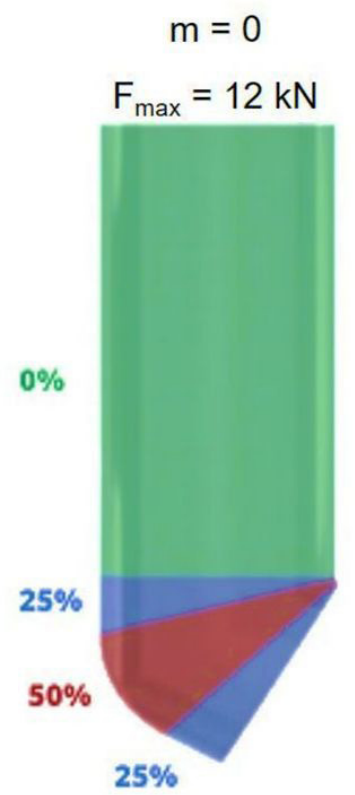

(a)

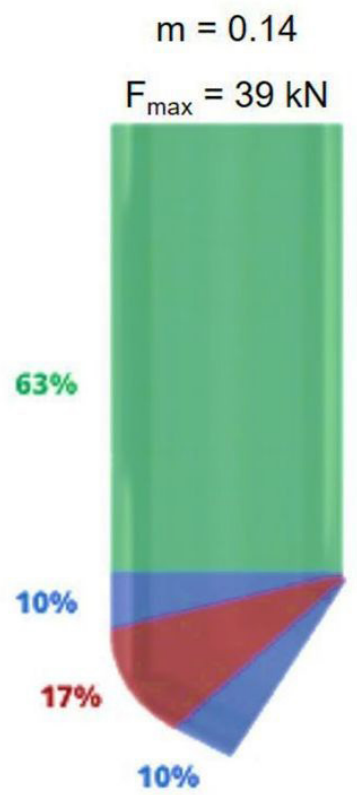

(b)

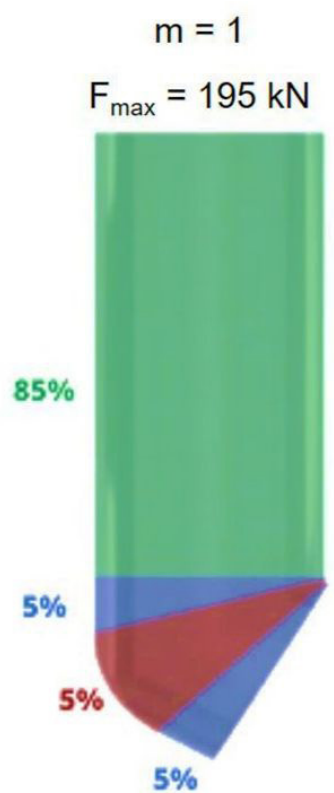

(c)

Figure 8. Influence of the friction factor on the power dissipation in each region of the ECAP die channel for a billet with a length of $30 \mathrm{~mm}$ : (a) $m=0$; (b) $m=0,14$; (c) $m=1$.

\section{Conclusions}

An upper-bound model was developed and used to analyze the ECAP process with circular cross section and an intersecting channel angle of $120^{\circ}$, and the following conclusions can be drawn:

- The maximum theoretical extrusion force was in a good agreement with the experimental results, being the analytical model useful to correctly dimension the tooling and to determine the process variables for ECAP different materials.

- The frictional power dissipated at entry surfaces between moving material and stationary ECAP die has a strong effect on the relative extrusion force and, therefore, an increase in the size of the ECAP billet significantly increases the loads required for processing.

- Lubricants should be correctly selected and used extensively during ECAP as it can reduce the maximum processing force in more than 15 times. A high constant friction factor at the die-material interfaces can make the operation unpractical due to the excessive stresses applied on the punch.

\section{Acknowledgments}

This work was supported by Coordination for the Improvement of Higher Education Personnel - CAPES [grant number 88882.447328/2019-01] and by Santa Catarina State Research and Innovation Support Foundation - FAPESC [grant number 2019-TR649 - 937/2019].

\section{References}

1. Harsha RN, Mithun Kulkarni V, Satish Babu B. Severe plastic deformation - a review. Mater Today Proc. 2018;5(10):22340-9.

2. Sadasivan N, Balasubramanian M, Rameshbapu BR. A comprehensive review on equal channel angular pressing of bulk metal and sheet metal process methodology and its varied applications. J Manuf Process. 2020;59:698-726.

3. Kim TN, Balakrishnan A, Lee BC, Kim WS, Smetana K, Park $\mathrm{JK}$, et al. In vitro biocompatibility of equal channel angular processed (ECAP) titanium. Biomed Mater. 2007;2(3):S117-20.

4. Valiev RZ, Langdon TG. Principles of equal-channel angular pressing as a processing tool for grain refinement. Prog Mater Sci. 2006;51(7):881-981.

5. Segal VM. Engineering and commercialization of equal channel angular extrusion (ECAE). Mater Sci Eng A. 2004;386(12):269-76.

6. Radhi HN, Aljassani AMH, Mohammed MT. Effect of ECAP on microstructure, mechanical and tribological properties of aluminum and brass alloys: a review. Mater Today Proc. 2019;26:2302-7. http://dx.doi.org/10.1016/j.matpr.2020.02.497.

7. Liang W, Bian L, Xie G, Zhang W, Wang H, Wang S. Transformation matrix analysis on the shear characteristics in multi-pass ECAP processing and predictive design of new ECAP routes. Mater Sci Eng A. 2010;527(21-22):5557-64. http://dx.doi.org/10.1016/j.msea.2010.05.058.

8. Wu WT, Jinn JT, Fischer CE. Modeling techniques in forming processes. Materials Park, OH: ASM International; 2003. p. 220-31.

9. Segal VM. Slip line solutions, deformation mode and loading history during equal channel angular extrusion. Mater Sci Eng A. 2003;345(1-2):36-46. http://dx.doi.org/10.1016/S09215093(02)00258-7.

10. Segal VM. Equal channel angular extrusion: from macromechanics to structure formation. Mater Sci Eng A. 1999;271(1-2):322-33. 
11. Segal VM. Plastic working of metals by simple shear. Russ Metall. 1981;V1:971-4.

12. Medeiros N, Moreira LP. Upper-bound analysis of die corner gap formation for strain-hardening materials in ECAP process. Comput Mater Sci. 2014;91:350-8.

13. Paydar MH, Reihanian M, Ebrahimi R, Dean TA, Moshksar MM. An upper-bound approach for equal channel angular extrusion with circular cross-section. J Mater Process Technol. 2008;198(1-3):48-53.

14. Medeiros N, Moreira LP, Bressan JD, Lins JFC, Gouvêa JP. Upper-bound sensitivity analysis of the ECAE process. Mater Sci Eng A. 2010;527(12):2831-44.

15. Aliha MRM, Shahheidari M, Bisadi M, Akbari M, Hossain S. Mechanical and metallurgical properties of dissimilar
AA6061-T6 and AA7277-T6 joint made by FSW technique. Int J Adv Manuf Technol. 2016;86(9-12):2551-65.

16. Iwahashi Y, Wang J, Horita Z, Nemoto M, Langdon TG. Principle of equal-channel angular peessing for the processing of ultrafine grained materials. Arthritis Care Res. 1995;55(2):322-4.

17. Ebrahimi R, Najafizadeh A. A new method for evaluation of friction in bulk metal forming. J Mater Process Technol. 2004;152(2):136-43.

18. R.V.S. Theory of Perfectly Plastic Solids. W. Prager and P. G. HodgeJun . John Wiley \& Sons, New York. Chapman \& Hall, London, 1951. 264 pages, index. \$5.50, 44s. net. J R Aeronaut Soc. 1952;56(497):396-396.

19. Hartley P, Pillinger I. Numerical modelling of material deformation processes. London: Springer London; 1992. 